\title{
Retrospective case series of fertility outcomes following laparoscopic resection of interstitial ectopic pregnancy.
}

\author{
Master M*, Hardy TSE, Wagaarachchi PT \\ Department of Obstetrics and Gynaecology, Women's and Children's Hospital, Australia
}

\begin{abstract}
Minimally-invasive surgery can improve outcomes in patients with interstitial ectopic pregnancies. However, it remains technically challenging and fertility outcomes following this procedure are not well documented. The aim of this study was to describe a laparoscopic surgical method to treat interstitial ectopic pregnancy using haemostatic sutures and bipolar excision and to assess future pregnancy outcomes in the eighteen women who underwent this operation. In all of the eighteen women, laparoscopic management was successful. Eleven women (61\%) reported thirteen subsequent pregnancies with one first trimester miscarriage, one termination of pregnancy, three normal vaginal deliveries and eight caesarean sections. Ten pregnancies (77\%) proceeded to term. There was one report of uterine rupture. We conclude that this minimally-invasive surgical method is a safe and effective procedure for the treatment of cornual ectopic pregnancy with preservation of future fertility, however elective caesarean section is recommended in subsequent pregnancies due to the risk of uterine rupture.
\end{abstract}

Keywords: Cornual pregnancy, Interstitial pregnancy, Ectopic pregnancy, Fertility, Laparoscopy

Accepted on November 21, 2018

What is already known on this subject?

Interstitial pregnancy is an uncommon condition, which needs prompt and effective treatment. Standard treatment is surgical excision and data on fertility after such treatment is limited.

- What are the implications of the study findings for clinical practice and/or further research?

A novel method of treating cornual ectopic pregnancy by laparoscopic excision is described. This involves applying haemostatic sutures and cauterization of the ascending uterine branch. This surgical approach is proven to be safe and effective and to preserve fertility. Hospitals that offer operative laparoscopy will be able to adopt this method, however endoscopic suturing skill of the operator is essential. Fertility rates described after this type of treatment should help in counseling patients.

\section{Introduction}

Interstitial ectopic pregnancy occurs when the conceptus implants within the intramural portion of the Fallopian tube [1]. It may occur in the context of spontaneous conception, IVF, heterotopic pregnancy [2] pregnancy with an IUCD in situ [3], and in the stump of a salpingectomy site following previous ectopic pregnancy [4]. Options for management include conservative, medical and surgical. Most authors agree that the high risk of complications including rupture and massive haemorrhage precludes expectant strategies [5]. Medical management includes intramuscular methotrexate, ultrasound or laparoscopically guided intra-sac methotrexate or potassium chloride. The advantages of local injection include administration of a smaller dosage and fewer systemic side effects. Although medical management has been demonstrated to be safe and effective in carefully selected patients, the risk of rupture requiring surgical intervention remains [6,7]. There is little data concerning tubal patency and future reproductive outcomes in this patient group.
In women whom medical or conservative management is contraindicated, traditional surgical management is to undertake laparotomy and resection of the cornual ectopic site $[8,1]$. Surgical management is made difficult by the position of the ectopic pregnancy with the need to avoid significant blood loss from the uterine arteries and difficulty in removing the pregnancy whilst still conserving the integrity of the uterus. Laparotomy with wedge resection, mini-cornual excision and hysterectomy has been advocated as appropriate methods of managing the risks associated with interstitial pregnancy.

More recently, many case reports have described minimallyinvasive methods to resect cornual ectopic pregnancies [9-11]. Laparoscopic cornual resection has been shown to have favourable outcomes and is associated with a similar complication rate to resection with laparotomy [12] and is now considered the preferred method of treating a cornual pregnancy [13]. Although most papers conclude that laparoscopic resection of cornual ectopic pregnancy is an appropriate option for fertility preservation [11], few series have reported data regarding pregnancy outcomes following the procedure. $\mathrm{Ng}$, et al. [14] published a retrospective review of 53 cases of laparoscopically treated cornual ectopic pregnancy. The pregnancy rate was $35 \%$ (18 patients). There were no cases of uterine rupture or dehiscence reported.

The aim of this case series is to describe the novel surgical method, sequel and future fertility outcomes in women who underwent a new method of laparoscopic resection of cornual ectopic pregnancy.

\section{Case Report Series}

\section{Materials and methods}

The Women's and Children's Hospital serves as a tertiary referral centre that provides advanced obstetrics and gynecology services in South Australia. Catchment area also includes transfers from the Northern Territory and far western New 
South Wales and Victoria. The gynaecology unit provides a general gynaecological service for women, but has a focus on advanced endoscopic procedures. There were 18 women who had laparoscopic resection of cornual ectopic pregnancy over a 12 year study period at this hospital (2004-2016). The patients were identified using coding records after ethics approval was granted. There were 29 cases identified by coding 'interstitial pregnancy'. Those which were managed non-surgically were excluded ( 9 cases). A further two cases were excluded as the surgical method used was not the procedure described in this paper. Only patients with cornual ectopic pregnancies managed with this specific laparoscopic technique were included in this case series. There were no abandoned cases. Case notes and electronic medical records were reviewed for clinical details, outcome of surgery and future fertility and pregnancy outcomes. The main outcome measure was the success of surgery and future fertility outcome. Given the study design, several limitations exist. The most significant being the small sample size which does not allow for application of statistics and selection bias. Also reliance on correct coding for the cases to be identified during the data collection process.

\section{Surgical technique}

Cornual ectopic pregnancy is visualized using standard laparoscopic procedure under a general anaesthetic. A disposable uterine manipulator is gently inserted. Procedure is commenced by bipolar coagulation of the round ligament on the side of the cornual ectopic. This opens the two leaves of the broad ligament exposing the ascending branch of the uterine artery, which usually is the principal blood supply to the ectopic pregnancy. Bipolar energy is used to coagulate this vessel. Next step is to coagulate and divide blood vessels in the meso-salpinx tributaries from ovarian vessels. Few (generally two to three) intra-coporeal haemostatic sutures (Vicryl) are then placed on the myometrium medial to the cornual ectopic bulge, which will almost completely de-vascularise the mass. Monopolar cutting current is used to excise the cornual ectopic along with the fallopian tube on that side. Specimen retrieval is done through Nubert Endo bag.

\section{Case Reports}

Clinical details and outcome for the 18 women who were treated for cornual ectopic pregnancy are summarised in Table 1. The majority of cases presented with pain and/or vaginal bleeding or ultrasound diagnosis of interstitial pregnancy. In three patients the diagnosis of cornual location was made intra-operatively. The sizes of the cornual ectopic pregnancies ranged from 14 $\mathrm{mm}-54 \mathrm{~mm}$.

The procedure was performed laparoscopically in all cases. Only one patient (Case 3 ) required blood transfusion postoperatively, in the context of a $2 \mathrm{~L}$ haemoperitoneum and postoperative haemoglobin $68 \mathrm{~g} / \mathrm{L}$. Estimated blood loss was minimal in all cases which had not previously ruptured and the only surgical complication was one accidental perforation of the uterus.

Previous ipsilateral salpingectomy for ectopic pregnancy had been performed in 8 cases $(44.4 \%)$. One patient (Case 14) previously had a laparotomy for management of a cornual ectopic on the right side. She then experienced recurrence on same side, which was treated according to the described method.
Subsequently, she went on to have two vaginal births.

All women were followed up to assess reproductive performance. Of these, seven did not have further pregnancies. There were thirteen pregnancies overall in the patient group, with one first trimester miscarriage, one termination of pregnancy, ten proceeding to term. Three women had normal vaginal deliveries at term. Case 13 had an emergency LSCS for failure to progress in the first stage of labour, but did not have any other complications. Case 8 involved a uterine rupture and is discussed in detail below. Case 17 had an elective caesarean section at $36+5$ weeks gestation for myometrial thinning seen on ultrasound.

Case 8 underwent a left salpingectomy in July 2008 and represented in November 2008 with right iliac fossa pain at 6 weeks gestation. Ultrasound demonstrated a live interstitial ectopic pregnancy in the residual stump of the left fallopian tube (CRL $3.4 \mathrm{~mm}$ ). These findings were confirmed on laparoscopy and the patient underwent a cornual resection without complication. In her subsequent pregnancy, she presented in spontaneous labour at term and complained of constant, severe abdominal pain. On examination she was peritonitic and a foot was palpated through the abdominal wall. There was no fetal distress. Emergency LSCS was performed demonstrating uterine rupture through the previous cornual resection site, with an extra-uterine fetal foot. Midline laparotomy with transverse lower segment incision was performed with delivery of a live male infant in good condition. Repair of the uterine rupture was successful and postoperative period was unremarkable.

The median time interval between the surgery for management of the cornual ectopic pregnancy and subsequent pregnancy (as per urine pregnancy test or ultrasound scan) was 18 (range 7-53 months) months.

\section{Discussion}

The aim of this case series was to assess the success of laparoscopic resection of interstitial ectopic pregnancy and subsequent reproductive outcome. Laparoscopic resection of interstitial pregnancy requires experience in minimallyinvasive techniques. The preservation of future fertility is a key consideration in patient management and this case series has provided evidence that pregnancy outcomes following laparoscopic cornual resection are promising. Despite these reassuring fertility outcomes, elective caesarean section remains the safest mode of delivery given the increased risk of uterine rupture in subsequent labour.

Although interstitial pregnancy is uncommon, occurring in $2 \%-4 \%$ of all ectopic pregnancies [7], it remains an important differential to consider in the context of ectopic pregnancy [15]. Our case series was typical of other reported case series, especially in demonstrating the association between previous salpingectomy and implantation of the pregnancy in the remaining cornual stump [16] and the risk of uterine rupture in future pregnancies [17].

Although medical management with intramuscular single-dose methotrexate has been demonstrated to be safe and effective in the majority of cases [6,7], definitive surgical management may be required in patients who are clinically unstable, or who do not meet institutional criteria regarding size of gestational sac and b-hCG level. Moreover, many cases are diagnosed at the time of 
Citation: Master M, Hardy TSE, Wagaarachchi PT. Retrospective case series of fertility outcomes following laparoscopic resection of interstitial ectopic pregnancy. Gynecol Reproduct Endocrinol-UK. 2018;2(3):11-14

Table 1. Patient characteristics, operative details and fertility outcome following laparoscopic resection of Cornual ectopic pregnancy.

\begin{tabular}{|c|c|c|c|c|c|c|c|}
\hline Case & Age & $\begin{array}{c}\text { G:P Gravidity } \\
\text { Parity }\end{array}$ & \begin{tabular}{|c|} 
Prior pregnancies \\
(ectopics \\
excluded)
\end{tabular} & Prior ectopic & Gestation & $\begin{array}{c}\text { Additional surgical } \\
\text { findings }\end{array}$ & $\begin{array}{c}\text { Fertility following } \\
\text { resection }\end{array}$ \\
\hline 1 & 37 & $4: 1$ & $\begin{array}{l}1 \times \mathrm{NVD} \\
1 \times \mathrm{M} / \mathrm{C}\end{array}$ & $1 \times \mathrm{R}$ salpingectomy & 6 & Nil & Nil \\
\hline 2 & 25 & $2: 1$ & $1 \times \mathrm{NVD}$ & Nil & $7+2$ & Nil & $1 \times \mathrm{M} / \mathrm{C}$ \\
\hline 3 & 36 & $4: 1$ & $\begin{array}{l}1 \times \mathrm{LSCS} \\
1 \times \mathrm{TOP}\end{array}$ & $1 \times$ L salpingectomy & 6 & $\begin{array}{c}\text { Ruptured } \\
\text { 2L haemoperitoneum } \\
3 \text { units PRBC }\end{array}$ & $\begin{array}{c}1 \times \text { Elective LSCS } \\
(\text { IVF) }\end{array}$ \\
\hline 4 & 43 & $2: 1$ & $1 \times$ forceps & Nil & uncertain & $\begin{array}{c}\text { L cornual excision } \\
\text { with salpingectomy }+\mathrm{R} \\
\text { sterilisation }\end{array}$ & Nil \\
\hline 5 & 40 & $3: 0$ & $1 \times \mathrm{M} / \mathrm{C}$ & $1 \times \mathrm{R}$ salpingectomy & $6+1$ & Nil & $\begin{array}{c}1 \times \text { Elective LSCS } \\
\text { (IVF) }\end{array}$ \\
\hline 6 & 24 & $3: 1$ & $1 \times \mathrm{NVD}$ & $1 \times \mathrm{R}$ salpingectomy & 4 & Nil & Nil \\
\hline 7 & 38 & $4: 2$ & $2 \times \mathrm{NVD}$ & $1 \times \mathrm{R}$ salpingectomy & 6 & Nil & Nil \\
\hline 8 & 33 & $3: 01$ & $1 \times$ ventouse & $1 \times$ L salpingectomy & 6 & Nil & $\begin{array}{l}1 \times \text { Emergency } \\
\text { LSCS for uterine } \\
\text { rupture }(\text { IVF) }\end{array}$ \\
\hline 9 & 32 & $1: 00$ & Nil & Nil & $8+3$ & Accidental perforation & Nil \\
\hline 10 & 42 & 7:01 & $\begin{array}{l}3 \times \mathrm{TOP} \\
1 \times \mathrm{NVD} \\
2 \times \mathrm{M} / \mathrm{C}\end{array}$ & Nil & $7+6$ & Nil & Nil \\
\hline 11 & 23 & $1: 00$ & Nil & Nil & $6+4$ & Nil & $\begin{array}{c}1 \times \text { TOP } \\
1 \times \text { Elective LSCS }\end{array}$ \\
\hline 12 & 27 & $2: 01$ & $1 \times$ NVD & Nil & $11+5$ & Nil & $1 \times$ NVD \\
\hline 13 & 39 & $2: 00$ & $1 \times \mathrm{M} / \mathrm{C}$ & Nil & 5 & Nil & $\begin{array}{l}1 \times \text { Emergency } \\
\text { LSCS }\end{array}$ \\
\hline 14 & 33 & $7: 04$ & $\begin{array}{l}4 \times \mathrm{NVD} \\
1 \times \mathrm{M} / \mathrm{C}\end{array}$ & $\begin{array}{c}1 \times \mathrm{R} \text { cornual ectopic } \\
\text { with Salpingectomy- } \\
\text { laprotomy }\end{array}$ & uncertain & $\begin{array}{l}\text { Recurrence on the same } \\
\text { side }(\mathrm{R})\end{array}$ & $2 \times \mathrm{NVD}$ \\
\hline 15 & 29 & $3: 01$ & $1 \times \mathrm{NVD}$ & Nil & 8 & Nil & $1 \times$ Elective LSCS \\
\hline 16 & 34 & $3: 01$ & $\begin{array}{l}1 \times \mathrm{LSCS} \\
1 \times \mathrm{M} / \mathrm{C}\end{array}$ & Nil & 9 & Nil & $1 \times$ Elective LSCS \\
\hline 17 & 25 & 9:01 & $\begin{array}{l}1 \times \mathrm{NVD} \\
5 \times \mathrm{M} / \mathrm{C} \\
1 \times \text { molar }\end{array}$ & $1 \times \mathrm{R}$ salpingectomy & 5 & Nil & $\begin{array}{c}1 \times \text { Elective LSCS } \\
(\text { IVF) (myometrial } \\
\text { thinning) }\end{array}$ \\
\hline 18 & 29 & $2: 00$ & $1 \times$ TOP & Nil & 6 & Nil & Nil \\
\hline
\end{tabular}

NVD: Normal Vaginal Delivery; LSCS: Lower Segment Caesarean Section; M/C: Miscarriage; TOP: Termination Of Pregnancy; IVF: In vitro Fertilization.

laparoscopy-three patients on our series. For these reasons, the development of safe, effective, and minimally-invasive surgical procedures for the treatment of interstitial ectopic pregnancy is desirable.

A major surgical consideration in the treatment of interstitial ectopic pregnancy is the use of techniques to achieve haemostasis prior to resection in order to reduce the risk of significant haemorrhage requiring conversion to laparotomy or hysterectomy in severe cases. Dilute vasopressin [18], electrocoagulation or uterine artery embolisation [19] have been used in most reported cases to reduce the risk of significant haemorrhage. The uniqueness of our surgical technique is due to isolation of the feeding branch of the uterine artery and placing haemostatic sutures in the adjacent myometrium prior to cornual resection and sealing the ascending uterine branch on the ipsilateral side. Bleeding from the excised area is negligible with this method. This was demonstrated to be effective even in the setting of acute bleeding due to ruptured cornual ectopic (Case 3). Cucinella, et al. [20] published a systematic review of the literature on surgical approaches to management of interstitial pregnancies. This showed reduced blood loss and operative times when haemostatic techniques were used. Laparoscopic 
injection of vasopressin into the myometrium below the cornual mass was the preferred method to minimize bleeding. Ansari, et al. [21] described temporary occlusion of the confluence of the utero-ovarian blood supply and the ascending branch using laparoscopic vascular clamp which may be quicker and easier, especially for the surgeons who do not perform laparoscopic suturing often. This may be considered to be an advance on the technique described in the current paper. Using temporary occlusive vascular clamps can potentially speed up surgery and further reduce blood loss [22].

Our technique is safe and can be performed with materials available in any theatre set up for standard laparoscopic gynaecological procedures. However, the surgeon should be competent in laparoscopic suturing techniques.

Fertility outcomes following this procedure are promising. Median time interval of a subsequent pregnancy was 18 months, which is comparable with tubal ectopic pregnancies. That information is useful in counseling patients with this uncommon condition. In those cases which proceeded to future pregnancy, two proceeded to normal vaginal delivery and another underwent the first stage of labour but proceeded to emergency caesarean section for failure to progress. All women had been advised that elective caesarean section was the safest mode of delivery for future pregnancies; However, those who laboured were managed according to the vaginal birth after caesarean (VBAC) protocol. Uterine rupture, a known complication of previous cornual resection [16] occurred in one case and was diagnosed rapidly with appropriate emergency surgery performed. Although neonatal outcomes were satisfactory in this and all other cases, it serves as another cautionary reminder about the risk of uterine rupture given the disruption of myometrial integrity, regardless of the technique [23].

\section{References}

1. Chetty M, Elson J. Treating non-tubal ectopic pregnancy. Best Pract Res Clin Obstet Gynaecol 2009;23:529-38.

2. Ben-Ami I, Panski M, Ushakov F, et al. Recurrent heterotopic pregnancy after bilateral salpingectomy in an IVF patient: Case report. J Assist Reprod Genet 2006;23:333-5.

3. Beltman JJ, de Groot CJM. Cornual pregnancy as a complication of the use of a levonorgestrel intrauterine device: A case report. J Med Case Rep 2009;3:8387.

4. Faleyimu BL, Igberase GO, Momoh MO. Ipsilateral ectopic pregnancy occurring in the stump of a previous ectopic site: A case report. Cases J 2008;1:343.

5. Lialios G, Kallitsaris A, Kabisios T, et al. Ruptured heterotopic interstitial pregnancy: A rare case of acute abdomen in a Jehovah's witness patient. Fertility and Sterility 2008;90:1200.e15-7.

6. Jermy K, Thomas J, Doo A, et al. The conservative treatment of interstitial pregnancy. British J Obstetr Gynecol 2004;111:1283-8.

7. Tang A, Baartz D, Khoo SK. A medical management of interstitial ectopic pregnancy: A 5-year clinical study. Aust N Z J Obstet Gynaecol 2006;46:107-11.

8. Moawad NS, Dayaratna S, Mahajan ST. Mini-cornual excision: A simple stepwise laparoscopic technique for the treatment of cornual pregnancy. J Society Laparoendoscopic Surgeons 2009;13:87-91.

9. Zuo X, Shen A, Chen M. Successful management of unruptured interstitial pregnancy in 17 consecutive cases by using laparoscopic surgery. Aust N Z J Obstet Gynaecol 2012;52:387-90.
10. Lee ES, Hahn HS, Park BJ, et al. Single-port laparoscopic cornual resection for a spontaneous cornual ectopic pregnancy following ipsilateral salpingectomy. Fertility and Sterility 2011;96:e106-10.

11. Tinelli A, Malvasi A, Pellegrino M, et al. Laparascopical management of cornual pregnancies: A report of three cases. European J Obstetr Gynecol Repr Biol 2010;151:199-202.

12. MacRae R, Olowu O, Rizzuto MI, et al. Diagnosis and laparoscopic management of 11 consecutive cases of cornual ectopic pregnancy. Arch Gynecol Obstet 2009;280:59-64.

13. Soriano D, Vicus D, Mashiach R, et al. Laparoscopic treatment of cornual pregnancy: A series of 20 consecutive cases. Fertility and Sterility 2008;90:839-43.

14. Ng S, Hamontri S, Chua I, et al. Laparoscopic management of 53 cases of cornual ectopic pregnancy. Fertility and Sterility 2009;92:448-52.

15. Larrain D, Marengo F, Bourdel N, et al. Proximal ectopic pregnancy: A descriptive general population-based study and results of different management option in 86 cases. Fertility and Sterility $2011 ; 95: 867-71$.

16. Tulandi T, Al-Jaroudi D. Interstitial pregnancy: Results generated from the society of reproductive surgeons registry. Obstetr Gynecol 2004;103:47-50.

17. Chatterjee J, Abdullah A, Sanusi FA, et al. A rare sequel following cornual ectopic pregnancy: A case report. BMJ Case Rep 2009:1614

18. Choi YS, Eun DS, Choi J, et al. Laparoscopic cornuotomy using a temporary tourniquet suture and diluted vasopressin injection in interstitial pregnancy. Fertility and Sterility 2009;91:1933-7.

19. Takeda A, Koyama K, Imoto S, et al. Successful management of interstitial pregnancy with fetal cardiac activity by laparoscopic assisted cornual resection with preoperative transcatheter uterine artery embolization. Arch Gynecol Obstetr 2009;280:305-8.

20. Cucinella G, Calagna G, Rotolo S, et al. Interstitial pregnancy: A 'road map' of surgical treatment based on a systematic review of the literature. Gynecol Obstet Invest 2014;78:141-9.

21. Ansari A, Ahmad S, James JA, et al. Robotic-assisted laparoscopic resection of cornual ectopic pregnancy: A case report. J Reprod Med 2015;60:58-64.

22. Grimbizis GF, Tsalikis T, Mikos T, et al. Case report: Laparoscopic treatment of a rupture interstitial pregnancy. Reproductive Biomedicine Online 2004;9:447-51.

23. Sentilhes L, Bouet PE, Gromez A, et al. Successful expectant management for a cornual heterotopic pregnancy. Fertility and Sterility 2009;91:934.

\section{*Correspondence to:}

\section{Mandana Master}

Department of Obstetrics and Gynaecology

Women's and Children's Hospital

Australia

E-mail: mandana master@hotmail.com 